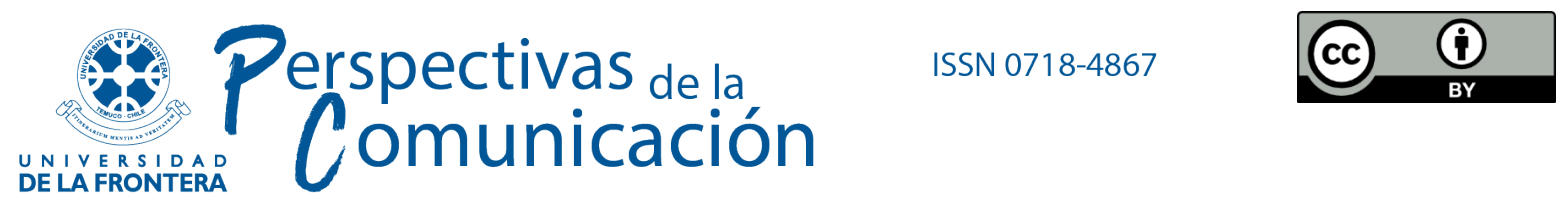

Artículo

\title{
ENTRE EL HUMOR Y EL TABÚ. LA MUERTE EN LA TRAMA COMUNICACIONAL.
}

DOI : POR ASIGNAR

Dra. Carolina Mazzetti Latini

In stitu to de Estu dios en Com unicación, Expresión y Tecnologías, IECET, CONICET, Universidad Nacional de

Córdoba, Córdoba, Argentina.

Univ ersidad Nacional de Cór doba, Facultad de Ciencias de la Comunica ción, Cór doba, Argentina.

mazzetticarolina@gmail.com

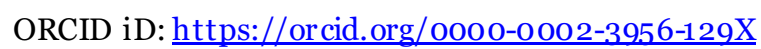

Recibido el 2020-11-13

Revisado el 2021-05-12

Ac eptado el 2021-05-12

Pu blicado el 2021-10-07

\section{Resumen}

La muerte como tema de conversación en la comunicación adquiere formas diversas a partir de distintos mecanismos de apertura y de cierre al diálogo, donde el despliegue de recursos personales e interpersonales desempeña un rol notable como articulador de los encuentros. A continuación, se ofrecen algunos registros acerca de las características que adquiere su presencia desde lo discursivo. El objetivo principal del estudio fue abordar los imaginarios sociales acerca de la muerte poniendo especial atención en las experiencias de personas mayores de la ciudad de Córdoba, Argentina. Los datos recabados se derivan del siguiente interrogante: ¿qué rasgos de inclusión/exclusión intervienen en el sostenimiento o abandono de conversaciones en torno a la muerte entre personas mayores? La pregunta procede de una investigación de tipo cualitativa basada en el análisis de experiencias desde un marco biográfico interpretativo. La recuperación de diferentes relatos sobre situaciones de conversación en el fluir de la vida cotidiana en los que se nombra a la muerte, o a los muertos, evidencia el sentido del humor y el tabú hacia la muerte como dos formas emergentes de los intercambios lingüísticos.

Palabras clave: muerte, comunicación, diálogo, personas mayores. 


\title{
BETWEEN HUMOUR AND TABOO. DEATH IN THE COMMUNICATIONAL PLOT.
}

\begin{abstract}
Death as a topic of conversation in communication acquires diverse forms through different mechanisms of opening and closing the dialogue, where the deployment of personal and interpersonal resources plays a notable role as an articulator of the encounters. In the following, we offer some records about the characteristics of its presence from the discursive point of view. The main objective of the study was to address the social imaginaries of death, paying special attention to the experiences of elderly people in the city of Córdoba, Argentina. The data collected is derived from the following question: what features of inclusion/exclusion are involved in the maintenance or abandonment of conversations about death among older people? The question stems from qualitative research based on the analysis of experiences from an interpretative biographical framework. The recovery of different accounts of conversational situations in the flow of everyday life in which death, or the dead, are mentioned, reveals the sense of humour and the taboo on death as two emerging forms of linguistic exchanges.
\end{abstract}

Keywords: death, communication, dialogue, elderly people. 


\section{Introducción}

La muerte se tramita desde la propia biografía, de ahí que constituya una gestión que se caracteriza por la diversidad constitutiva en cuanto a su vivencia, comprensión y significado. Por ello, hablar, nombrar o dialogar sobre la muerte y los muertos, motiva e impacta de distintas maneras a las personas que sostienen una conversación al respecto; sea breve, extensa, profunda o pasajera. En tanto temática argumental, la muerte versa entre un carácter protagónico y apariciones secundarias, tangenciales o solapadas. De modo que es nombrada de manera directa o indirecta, variando su contexto de aparición. Al respecto, Elias (2009) afirma que, si bien en la Edad Media se hablaba más frecuente y abiertamente de la muerte, como así también era un asunto de jóvenes y viejos, eso no significaba que en el pasado se muriera más en paz o que el nivel social del miedo permaneciera inmutable. La expansión de la peste, el escaso desarrollo de drogas para paliar el sufrimiento, el crecimiento de las ciudades, el miedo infundido por la iglesia son solo algunos de los datos que le permiten al autor poner en cuestión el argumento de Ariès (2008, 2011,) acerca de la revalorización de la muerte en tiempos pasados. Es decir, que desde el siglo V al XII la muerte no generaba un gran impacto porque estaba incluida en la vida de la comunidad. De ahí la denominación atribuida por Ariès como muerte domesticada o domada.

La exposición que aquí se presenta se deriva de una investigación doctoral, la cual se enmarca en el área disciplinar de la comunicación desde la teoría de lo imaginario social a partir de los aportes de Cornelius Castoriadis (2010). Reconociendo la contribución de este enfoque teórico al campo disciplinar (Dittus, 2006; Cabrera, 2004, 2007, 2008; Pintos, 2005), el objetivo principal del estudio fue abordar los imaginarios sociales acerca de la muerte poniendo especial atención en las experiencias de personas mayores de la ciudad de Córdoba, Argentina. A continuación, se exponen los datos recabados a partir del siguiente interrogante planteado: ¿qué rasgos de inclusión/exclusión intervienen en el sostenimiento o abandono de conversaciones en torno a la muerte entre personas mayores? Cabe advertir que, si bien no se procura generalizar todas las formas o recurrencias que asume la muerte en las conversaciones que mantienen las personas mayores - pretensión inabarcable- sí se ofrecen algunos registros acerca de las características que adquiere su presencia desde lo discursivo. $\mathrm{O}$ sea, se recuperan distintos relatos sobre situaciones de conversación en el fluir de la vida cotidiana en los que se nombra a la muerte o a los muertos, en encuentros con otros cercanos (pareja, amistades, familia, compañeros, etc.). En tanto el acceso a la realidad social es, fundamentalmente, un acceso mediado por los discursos de los sujetos (Martín, 1998), no se abordan las conversaciones de manera directa, sino que se recuperan a partir

Pers pectivas de la Comunicación - Vol. 14 - No2 - 2021 - pp. 95-125

Universidad de la Frontera - Chile 
de lo que las personas entrevistadas mencionan sobre esos diálogos. A propósito, el humor y el tabú aparecen como nociones que articulan los rasgos de inclusión/exclusión que intervienen en el sostenimiento o abandono de conversaciones en torno a la muerte. Entendiendo por rasgos, aquellos aspectos y/o elementos lingüísticos o paralingüísticos que motivan la presencia o la ausencia de la muerte en las conversaciones.

\section{Método}

La estrategia teórica-metodológica del estudio se sostuvo en un diseño de investigación cualitativa basado en el análisis de relatos (experiencias) desde un marco biográfico interpretativo (Denzin \& Lincoln, 1994; Vasilachis, 2006) siendo la entrevista biográfica la técnica de recolección de información elegida. El perfil de las personas mayores se definió a partir de criterios teóricos según el criterio del investigador donde se trabajó con una muestra intencional en combinación con el muestreo en cadena o por redes ("bola de nieve") (Hernández-Sampieri, Fernández-Collado \& Baptista-Lucio, 2014).

La investigación profundizó en las experiencias de mujeresy varones de más de 60 años que, en conjunto, recorren la mayor parte de la tercera edad representando diferentes posiciones en el curso de la vida. En el contacto con los informantes claves se priorizó la conformación de una muestra heterogénea teniendo en cuenta sexo, edad y variables socioeconómicas como nivel de instrucción, situación civil y composición familiar. La muestra focalizó en: 1) personas mayores autoválidas, física, psíquica y socialmente (que pudieran garantizar el cumplimiento de sus necesidades personales); 2) que fueran mujeres y varones; 3) que tuvieran 60 años o más, por lo que, la muestra abarcó personas mayores nacidas entre 1923 y 1954. Además, se tuvo en cuenta: 4) que estuvieran casadas, viudas y separadas o divorciadas; 5) que vivieran solas, en pareja o con algún familiar; 6) que fueran personas con y sin hijos; 7) que tuvieran diferentes trayectorias educativas (primaria, secundaria y terciaria o universitaria); 8) que habitaran en diferentes zonas de la ciudad; 9) que tuvieran estilos de vida activos y autónomos, entendiendo por esto, hábitos de socialización y/o realización de actividades de aprendizaje o recreación con pares. También se tuvo en cuenta que: 10) las capacidades cognitivas y físicas les permitiera sostener un diálogo fluido; y que, en consecuencia, la disposición para compartir su experiencia habilitara el encuentro.

Las entrevistas se realizaron durante 2017 y 2018. En total fueron entrevistadas 29 personas de distintas cohortes, de las cuales 16 fueron mujeres y 13 fueron varones, correspondientes a los siguientes rangos de edad: de 60 a 69 años ( 9 casos); 70 a 79 años (11 casos); de 80 a 
89 años (8 casos); de 90 a 99 años (1 caso). La cantidad de entrevistas a realizar se precisó por saturación teórica, tal como lo explicita la teoría fundamentada, metodología utilizada (Glaser \& Strauss, 1967; Murillo, 2003). Por supuesto, la participación fue libre, voluntaria, individual y confidencial (Consejo Nacional de Investigaciones Científicas y Técnicas [CONICET], 2006). En lo que respecta a las implicaciones éticas del trabajo los principios de autonomía, beneficencia, no maleficencia y justicia (Berenguer, Fernández \& Pons, 2014; Loue, Comité Central de Bioética \& Molina, 2015) se asumieron desde los inicios de la investigación para no dañar a ninguno de los involucrados.

\section{Resultados}

\subsection{Conversaciones sobre la propia muerte}

En el plano íntimo las personas mayores entrevistadas mencionan conversaciones mantenidas con hijos/as, hermanos/as, pareja o amistades, e incluso madres o padres, en las que se hace referencia a la propia muerte. Según lo expresado, al manifestar los deseos personales acerca del propio destino corporal, las reacciones suscitadas por parte de los interlocutores adquieren distintas direcciones. Entre las formas emergentes, se destacan en las conversaciones: la tensión, las actitudes evasivas, la postergación, la interrupción y la clausura en torno al tema, como así también, la receptividad, la disposición a la escucha activa, la complicidad y la invocación del humor como plataforma y dispositivo unilateral o de intercambio recíproco. Por consiguiente, se destacan algunos de los fragmentos que dan cuenta de distintos escenarios y situaciones. Durante la entrevista, una mujer de 88 años narra, brevemente, la reacción de sus hijos cuando ella les comunica su deseo final:

(E): Com oy o siem pre les digo a mis hijos "llegó el mom ento de la muerte. Ya tengo más o m enos casi todo arreglado. Sin velatorioy directamente la cremación".

(Inv):Y ¿qué le dicen cuando usted les dice eso?

(E): "Mamá nohables de eso". Pero saben quetiene que ser así.

(AL, mujer de 88 años)

El relato acerca de la expresión de su voluntad evidencia el pedido de no continuar hablando al respecto. De modo que, el diálogo con sus hijos en torno al tema de su muerte se clausura. Sin embargo, quien testimonia, y en respuesta hacia quien la entrevista, aclara: "pero saben que tiene que ser así”. Es decir que, aunque no se profundice la conversación sobre el tema, su frase expone un saber compartido que se corresponde con cierto orden de lo implícito. En

Pers pectivas de la Comunicación - Vol. 14 - No2 - 2021 - pp. 95-125

Universidad de la Frontera - Chile 
la misma línea, otra mujer que instala el tema en su entorno familiar luego de anoticiarse sobre la muerte repentina de un reconocido periodista que apenas superaba en edad, comenta sobre la actitud de sus hijos al referir a su propia muerte. Su relato expone tanto el silencio como el pedido de postergación de la conversación:

Y hoy mi hijo me escuchó y no me contestó nada... mi hija capaz me dice “ah mamá esos temas no toquem os ahora”. (...) Pero hoy día justamente comenté sobre el periodista que falleció de un aneurisma, el de TN. 62 años, tan joven. Si yo quetengo 63 no me sientotodavía para partir... por que es cierto uno todavía se sientejoven.

(MI, mujer de 63 años)

A continuación, mientras una mujer profundiza sobre la cobertura de sepelio de su tía fallecida, declara, en el marco de la conversación -que califica de desagradable dado el tema de la charla-, la negativa por parte de sus hijos de hablar sobre los aspectos preparatorios de su muerte:

(E): Cuando falleciómi tía yo no puse un peso. Agarré la póliza y se la llevé. Y claro Carusso [empresa de servicios fúnebres] es un cheque al portador. Yo no moví un dedo. No movíu nedo. Loúnico es que v os tenes que buscar... bueno un poco desagradable la conversación [aclara sobre el tema al que hace referencia], lo único quetenes que buscar es el lugar donde la vas a colocar (...)

(Inv):Y ¿̇usted ha manifestado algún deseo en relación con si quiere que depositen sus cenizas en algún lugar?

(E): Ah sí. Ahí está en un bor rador [señala el modular de su casa]. Le quiero agregar cosas, pero ahora me da cosa vos sabes. Me pongo mal [debido a una enfermedad reciente que la afectó em ocionalmente]. Peroahí hay un papel... ninguno de mis hijos quierehablar ese tema.

(Inv):Ah noquieren hablar del tema...

(E): No, noquieren. "Mami deja de hablar macanas", "no, no...". El día que a míme pase algo nadieva a saber dónde tienen que ir. Entonces, como nadie me llevaba el apunte un día me puse (...) hay un folleto que dice que es lo que hay que hacer. Es más, les he puesto "si les llega a sobrar un peso, repártanselo entre los tres, pero no se peleen. Los amo mucho"y les hice un corazón grande abajo [mientras dibuja con su dedoel corazón en la mesa]. Está todo el testamento.

(Inv): Es un testamento que ha hechou sted.

(E): Es un borrador. Y saben que está ahí. Por que ellos no saben ni mi número de cu enta ni nada. Ellos saben que pago Carusso porque les llevo la póliza. Pero nada más. Y ahí están las indicaciones. Y que después tienen queir al Anses. Y está todo ahíporque nadie quiere hablar de ese tema.

(Inv):Y cuando ellos le dicen que prefieren no hablar ¿̇usted se los respeta?

(E): Ah sí, peroyo les digo que el día que a mí me pase algo no van a saber... pero a hora noles digo nada, porque yoy a les he dicho queahí están las in dicaciones.

(OC, mujer de 72 años) 
Ante la negación de sus hijos sobre mantener una conversación acerca de sus deseos finales y cómo proceder en asuntos administrativos, la entrevistada afirma respetarles su voluntad sin insistir al respecto. Aunque, según argumenta "como nadie me llevaba el apunte (...) porque nadie quiere hablar de ese tema”, además de entregarles la póliza de su seguro de sepelio, les expresa por escrito en un testamento "borrador" -confeccionado por ella misma- las indicaciones a seguir llegado el momento de su muerte. Asimismo, también reconoce su deseo de "agregar cosas", sin embargo, dicha labor le genera un malestar dada su reciente enfermedad.

Por el contrario, en el siguiente testimonio una mujer comenta sobre la conversación mantenida con su marido en reiteradas oportunidades:

No le tengo miedo a la muerte. Es más, lohem os habladovarias veces con mi marido "si a mí me pasa algo, a mí me desconectas, no me alargues" ... "si no hay necesidad, si no hay posibilidad, no me alargues". Y yole dije "el día que vos notengas posibilidad yo note voy a alargar". "Ya lo sé", me dice.

(RH, mujer de 70 años)

La entrevistada sentencia con vehemencia el pedido explícito que le hace a su marido de que le evite la prolongación de su vida ante una posible situación irreversible, proclamando para sí misma, y para él también, el deseo de una muerte digna. Es decir, la propia muerte expresada en términos de muerte deseada es motivo de conversación entre esposos.

En otro testimonio, una mujer de 67 años refiere a momentos de conversación en los que, de manera recurrente, aparece la muerte como tema de preocupación, aunque evocada en el diálogo a partir de la inquietud de su madre. Es decir, es la madre, quien, como interlocutora insiste en diferentes instancias al manifestar distintas preocupaciones vinculadasa su propia muerte. Más precisamente, aparecen temores acerca del destino de sus pertenencias, interrogantes sobre el desenlace de su muerte, e indecisión sobre la inhumación de sus restos. Al respecto, la entrevistada relata la angustia que le genera la "fijación" de su madre en relación con la muerte:

Me pone mal muchas veces cuando mi mamá se preocupa y dice “cuando y o me muera acá está la escritura, cuando y o m e muera acordate de... cuando yo me muera esto...”, “iBasta! basta, ya se verá cuando te mueras". Yo a ese problema no lo tengo... cuando yo me muera no sé qué irán a hacer con esto, si irán a tirarlo, no sé, no es mi preocupación ya estaría muerta. Yo hoy vivo y ya está. Esa es mi preocupación, vivir hoy, mañana, el tiempo que me quede. (...) “cuandoyo me muera quiero que ustedes

Pers pectivas de la Comunicación - Vol. 14 - No2 - 2021 - pp. 95-125

Universidad de la Frontera - Chile 
no tengan que arreglar tal cosa entonces yo ahora lo v oy a arreglar para que ustedes no tengan problem as" entonces le digo "deja de gastar plata, aprovechala, andate a pasear” ... "no, no, yo pienso en ustedes” ... el sábado pasado me hizo subir a la moto ${ }^{1}$ porque quiere arreglar la casa, venderla. Entonces yole pregunto qué se va a com prary me dice que se va a ir con unas monjitas, por que no se v a a ir a un geriátrico. Entonces la parteque a ella le corresponde se lava a dar a las monjitasy la pensión de mi papá. A míse me em pieza a subir toda u na cosa... vos no sabes que malque vengo de allá, vengo a una velocidad con el auto que pienso que algún día me voy a estrellar de la bronca que me da que me diga esas cosas. Y ahí entramos, no sé si a discutir, peroy ole digo “¿por qué pensas en esas cosas?” ... "porque hay que pen sarlas y bla, bla..." y yole digo "pensa que tenes 85 años y estas de diez, m ejor que y o (...) perotien e esa fijación de que se v a m orir, qu e cómo se v a a m orir, que geriátrico, quecuando se muera que la pongan así, que un día la entierren, que otro día m ejor que nola cremen por que el papa dice que hay castigo, que Dios te v a castigar (...)

(Inv):Y cuando usted la calla a su mamá, ella ċcómo reacciona?

(E): Y ella hace así (alza los hom bros, su spira, hace gestos faciales). Me tom a com o que yo soy, no sé si la palabra es despreocupada... "Esta vaya a saber que va a hacer de su vida" una cosa así viste. Como que y o nole doy bolilla a esa s cosas... "vaya a saber que me va a pasar a mí”, dice así, y no sabe lo mal que me pone, no mal, sino que me pone loca cuando empieza a hablar esas cosas. Por que me pareceque es al vicio, para que vamos a pensar en loque va a pasar.

(LP, mujer de 67 años)

Se manifiesta en el relato que la preocupación de su madre acerca de la muerte se articula con sus propias concepciones. En tanto que, para la entrevistada, la muerte no es un tema de preocupación, argumentando: "Yo hoy vivo y ya está. Esa es mi preocupación, vivir hoy, mañana, el tiempo que me quede". Actitud que condice con la frase destinada a su madre: “iBasta! basta, ya se verá cuando te mueras”, pronunciada cuando su madre le recuerda donde está la escritura de su casa y demás aspectos preparatorios. El malestar quele provoca a la entrevistada las reiteradas evocaciones de su madre acerca de la manifestación de su voluntad anticipada vinculada al final de la vida, le imposibilita sostener un diálogo fluido y sereno sobre el tema. Al contrario, la conversación la moviliza al punto de angustiarla. Si bien, el diálogo no se clausura, adquiere rasgos de tensión: "Y ahí entramos, no sé si a discutir". En ese marco, la entrevistada narra la pregunta que le hace a su madre: "yo le digo ¿por qué pensas en esas cosas?” a lo que, según el propio relato, su madre le responde “porque hay que pensarlas" y a continuación la entrevistada agrega "y bla, bla...”, cual letanía, en referencia a los comentarios de su madre al referir al tema.

1 Expresión coloquial para expresar alteración, nerviosismoy/o enojo. 
Reflexionar, decidir y elabor ar intersubjetivamente cuestion es que afectan la organización sobre el final de la propia vida resulta aliviador para m uchas per son as m ayor es. A m enudo ocu rre que son los otros quienes no permiten que se establezca un espacio de diálogo sobre estos temas (Pochintesta, 2012, p. 11).

En otras circunstancias, las conversaciones para referir a los deseos personales al final de la vida se sostienen en un marco de apertura dispuesta hacia la escucha y el diálogo afable. A propósito, la misma mujer que testimonia la indignación que le provoca la fijación (sic) de su madre con la muerte, relata un diálogo mantenido con una amiga y con uno de sus hijos:

(E): Lo único sí que le dije a una compañera del taller, queíbamos a cantojuntas, yole dije "cuando yo me muero, si mellego a morir -hablábamos una vez-, a míme encantan las m argaritas sabes”. Mi hijo me dijo "mamá ¿no podés elegir otra flor más linda? son lindas, pero va a haber un olorón" [risas] "y v os María Inés me cantas ese tango que tanto me gusta que se llama Como dos extraños" ... "estás loca, mira si voy a ir velorio a cantar, me van a sa car cor riendo" me dice. Enton ces yole dije, "vos lo buscas a Sergio y le decís, tu mamá me dijo que le cante Como dos extraños, y ahí nomás Sergio te prepara la fiesta y cantas" [risas] Y Ser gio me dijo "sí mamá yo notengo problema, yo preparo todo".

(Inv): Usted le dijo a su hijo...

(E): Sí, le conté. Le dije, contándole lo que me había dicho la María Inés que tenía miedo de que la sacar an corriendo m is otros hijos. Entonces "yole dije que hablé con vos. Te aviso por cualquier cosa" (...) y o a la muertela tomo com o parte de la vida. No sé cuándo me toque comoiré a estar y si pensaré si es parte de la vida. Perohoy noes mi preocupación.

(LP, mujer de 67 años)

En el testimonio, la entrevistada describe las indicaciones solicitadas a su amiga y comunicadas a uno de sus hijos como garantía de la concreción de sus deseos personales al momento de su muerte. En el relato, su hijo la escucha, apela al humor y le garantiza tranquilidad en torno a la concreción de su deseo. Asimismo, la entrevistada relata cómo la muerte aparece en conversaciones con compañeras de su edad e incluso mayores que ella:

(E): Hay algunas viejitas que dicen "yotengo unos a chaques y me pu edo m or ir" (...) Cu ando hablan de la muerte yolas escucho. Cuando dicen alguna cosa me rio, sino no... no, no, no pienso. Nunca me he pu esto a analizar, no sé si será tabú para otra gente. Perov eo que sí piensan en la muerte, si, si piensan en la muerte. La veo a mi mamá también. Que piensa en su muerte.

(Inv ): Pero en general, en su entorno, ¿̇podría decir que es la gente más bien más grandeentonces?

(E): Sí, sí, la gente más grande. Las que son mis compinches, las que tenemos la misma edad, eh, no, no pensam os en la muerte.

(Inv):Y cuando hablan al respecto por ejemplo ¿̇qué dicen?

(E): Algunas por ahí dicen "no hablemos de estas cosas. No hablemos".

Pers pectivas de la Comunicación - Vol. $14-N^{0} 2-2021-$ pp. 95-125

Universidad de la Frontera - Chile 
(Inv): ¿Hacen chistes por ejemplo?

(E): Sí, esto de las flor es te imaginas qu evenga la María Inés con las Margaritas... Sergio dice “mamá va a haber un olor a culo" (...) O pensar a María Inés cantando al lado del cajón... sí, nos reímos de esas cosas. Pero no para decir "no hablemos que me voy a morir”...no.

(LP, mujer de 67 años)

El relato ratifica la presencia del pensamiento sobre la muerte por parte de su madre y de sus compañeras. Como tema de preocupación y conversación, el pensamiento se materializa en los comentarios y alusiones verbalizadas en los encuentros compartidos entre la entrevistada y sus compañeras de taller. Las frases afirman la presencia de la muerte en tanto posibilidad, como así también orientan la clausura de la conversación. A diferencia de los intercambios mantenidos con su madre, en compañía de amistades la entrevistada dice manifestar actitud de escucha y complicidad desde el gesto de la risa. Es decir, el humor aparece en los relatos para referir a la muerte, siendo utilizado como estrategia retórica, tanto por parte de los interlocutores, como por parte de quien habla sobre su propia muerte o sus últimos deseos al morir.

\section{El sentido del humor en torno a la muerte}

El humor refiere a una disposición de ánimo que contempla lo cómico (Casares, 2002). Sin embargo, Martin (2001) afirma que recién en el siglo XVI el humor ingresa en el campo de lo cómico. Asimismo, señala que el sentido del humor es un concepto amplio y multifacético que alude a características de estímulos (relatos, películas, historietas); procesos mentales en torno a la creación, percepción y comprensión de situaciones humorísticas; como a respuestas frente a situaciones diversas. Incluso, así como se manifiesta en situaciones interpersonales, también indica que puede ser un fenómeno exclusivamente intrapsíquico. Algunos autores definen el sentido del humor como una forma específica del estado afectivo y emocional (Fernández-Abascal, 2009); o como un rasgo de personalidad o fortaleza del carácter, que se asocia a comportamientos positivos a los que se le atribuyen beneficios físicos, psicológicos y sociales (Carbelo \& Jáuregui, 2006; Martin \& Ford, 2007). Así como hay estudios que indican que el sentido del humor es un factor protector de la salud porque aporta mejor calidad de vida (Labarca, 2012); otros especialistas aseguran que no todos los tipos de humor provocan ajustes positivos (Erickson \& Feldstein, 2007), pudiendo beneficiar o no la salud física o psicológica (Kuiper et al., 2004; Maurer, 2008). 
Se trata de una palabra asociada a un abanico de nociones que expone en su manifestación física -originaria o residual- la sonrisa, la risotada o la carcajada. Sin embargo, el humor no se restringe a una dimensión física, sino que, fundamentalmente, se caracteriza por una dimensión cognitiva, comportamental, afectiva y social (Fernández-Abascal, 2009). Es decir, es una capacidad humana que genera desplazamientos y permite la articulación de las emociones, sentimientos, pensamientos y creencias. En tanto construcción sociocultural fruto de una dinámica colectiva, el humor se renueva y actualiza en la trama comunicacional, posibilitando la socialización entre pares y/o desconocidos. En cuanto a su contenido, es diverso, incluso cuando la muerte es objeto de broma, adquiere distintas formas y argumentos expresivos.

A continuación, por un lado, una mujer recuerda el chiste dirigido a un familiar al imaginarse muerta en el cajón: "Pero yo digo que no quiero lágrimas. Y ċsabes la broma que le hice?... y me ponen una radio en el cajón para cuando yo esté aburrida, así escucho música [risas]... es un decir viste..." (CC, mujer de 77 años). Como si burlara a su propia muerte, la música le permitiría a la entrevistada salir del aburrimiento en su condición de muerta; broma que refuerza su pedido al expresar: "no quiero lágrimas".

Por otro lado, como el humor permite reproducir temores en una dimensión teatralizada, una mujer relata una broma realizada a su amiga, quien le manifiesta el temor de que algo grave le suceda. Con la intención de hacerla reaccionar desde el humor, la entrevistada refiere a la muerte de manera solapada, es decir, aludiendo a ella como "algo grave" pero sin nombrarla (en los mismos términos que su amiga lo plantea): "Yo por ahí la bromeaba porque a ella le gusta bromear. Le digo 'escúchame si a vos te paso algo grave, si te rompen la puerta, vos no la vas a tener que arreglar' ... así la bromeaba" (AF, mujer de 62 años). Aquí el humor es utilizado como estrategia para enfrentar el temor de su amiga, aliviando la tensión generada por la preocupación manifiesta.

Es una constante que el humor en torno a la muerte adquiere diversas manifestaciones y cobra presencia en diferentes escenarios. A propósito, un entrevistado responde introduciendo en el juego del humor a quien lo entrevista:

(Inv ): Si tuvieras queponerle un color a la muerte ¿̇ué color le pondrías?

(E): Hay es que no había pen sado nunca en la muerte yo[risas]

(Inv):[Risas]

( $\mathrm{RC}, \mathrm{v}$ arón de 86 años)

Pers pectivas de la Comunicación - Vol. $14-N^{0} 2-2021-$ pp. 95-125

Universidad de la Frontera - Chile 
Otro testimonio, relata sobre el pago mensual del seguro de sepelio:

(E): (...) actualmentelo pagoyo [al seguro de sepelio] y de vezen cuandovoy, sa cola póliza y se la llevo a mi hija. Porque yo no me voy a poder hacer los trámites mamita [risas]. (...)Ya le hedicho a miyerno (...) es mi amigo, es mi confidente y es un hijo. No sabes lo que es ese chico. Y me sabe decir "Bueno su egra ¿̇cuándo vas a usar lo que estas pagando?"[risas].

(Inv): [Risas] Le hace bromas.

(E): iSí!

(OC, mujer de 72 años)

Aquí el guiño cómico es de doble dirección. Por un lado, y de manera cómplice, con quien la entrevista, al enunciar en el marco de la charla: "Porque yo no me voy a poder hacer los trámites mamita [risas]”. Y, por otro lado, al aludir a su yerno que, en tono chistoso la provoca, preguntándole cuando usará el seguro de sepelio que paga la entrevistada. "La apreciación del humor, como dimensión del sentido del humor, hace referencia al grado de diversión que se experimenta como respuesta ante un determinado estímulo humorístico" (Carretero-Dios, Pérez-Meléndez \& Buela-Casal, 2006, p. 466).

Seguidamente, el humor como recurso asume un rol protagónico en las conversaciones íntimas entre madre e hija para referir a la muerte de la entrevistada:

(E): Yo siem pre hablo con mi hija sobre este tema y siempre le digo "el día que y o me muera si vos quer es hacer una ceremonia, hacelo. Pero sino, ya sabes que mi cuerpo se tieneque convertir en cenizas. Y las cenizas, si es posible, dejalas en un lugar don de cor ra el agua". Esa es la in dicación que yotengo. "No le dejes las cosas a tu hermano porque me va a tener velando una semana"[risas]... Tipogitano... "no, no, v os trata de ser rápida con el trámite".

(Inv ): [risas] O sea que usted identifica que lo resolverían de for m a distinta...

(E): Claro, exactamente. Él es un boh emio "uh mi mamá no sé dónde tiene el documento"... "yo voy a dar v ueltas una sem ana", le digo.

(Inv ):Y cuando usted le com unica estas cosas a su hija ¿̇quéle dice ella?

(E): Ella lo tom a naturalmente. A veces cuando y o me enfermo le digo "uh tengo que com prar estos rem edios que están tan caros... que me van sumando medicamentos" entonces ella me dice en broma "ientregate mamá vamos!"[risas].

(Inv): [Risas].

(E): "Entregate" dice [risas] "y o tengo mucho que a prender en esta vida como para entregarme"le digo [risas].

(AG, mujer de 70 años) 
Por una parte, y en consonancia con el imperativo psicoanalítico acerca de la imposibilidad de concebir la propia muerte (fin de la existencia), la proyección imaginaria de su velatorio en el caso de que fuera organizado por su hijo - a quien reconoce como bohemio-, es relatada por la entrevistada desde el plano de la vida y en términos jocosos al imaginarse en su velorio dando vueltas durante una semana al estilo gitano, según sus propios términos. "Mientras que cada sujeto en el plano inconsciente está persuadido de su inmortalidad, el humor podría aparecer como la reivindicación de esta" (Coppin \& Gaspard, 2017, p. 157). Si bien, una hora, un día o una semana de velorio no modificaría su condición de fallecida, la imaginación de la escena es construida desde la dificultad de admitir la propia muerte, ya que, en términos de Freud (1915) en el inconsciente cada uno está convencido de su inmortalidad. Para este enfoque la muerte siempre es una experiencia del otro, con lo cual las ideas o representaciones son limitadas. De ahí que, en su relato sobreviva como observadora, es decir, la entrevistada se vuelve testigo de su propia muerte, aunque sin participar en ella. Por otra parte, previa aclaración de que su cuerpo debe convertirse en cenizas dice encargarle a su hija la tarea de resolver rápidamente el destino de sus restos. Incluso explicita que es, justamente con ella, con quien siempre habla sobre el tema, o sea, sobre su propia muerte. De modo que, su comentario sería asumido "naturalmente" por parte de su hija según el relato. Actitud que se confirma, luego, con la destreza humorística de la frase: “ientregate mamá vamos!”. Expresión provocadora que incita a que su madre se entregue a la muerte.

El humor, en sus distintas manifestaciones lingüísticas, paralingüísticas y físico-corporales (gestos, posturas, sonrisa, risa, carcajada, etc.), forma parte de los diversos recursos de la comunicación humana. Sin embargo, su contenido varía según la personalidad, la disposición personal, el vínculo y la confianza entre los interlocutores, el devenir de la conversación, el nivel de intimidad, la situación o momento, el contexto, entre otros factores. Por lo que, en tanto estado afectivo hacia algo o alguien, el humor acerca de la muerte se evidencia en comentarios espontáneos, benignos y sutiles, como así también en expresiones caracterizadas por la metáfora, el sarcasmo y la ironía.

A propósito, un testimonio confirma que la muerte es motivo de conversación entre pares, pero desde el humor porque "se trata de pasarla bien. No de tirarte abajo" (AA, varón de 71 años). El entrevistado relata dos bromas entre amigos en torno a la muerte. La primera narración evoca una situación acontecida durante un paseo grupal entre amistades. "Habíamos desayunado y él [amigo del entrevistado] no venía entonces dice uno ' che anda

Pers pectivas de la Comunicación - Vol. 14 - No2 - 2021 - pp. 95-125

Universidad de la Frontera - Chile 
a ver si no se siente olor a cala' [risas]”. La alusión a las calas connota el cementerio, ya que es un tipo de flor que, en estas latitudes, suele utilizarse en los rituales fúnebres. En la misma conversación, aunque haciendo referencia a otra situación, el entrevistado comenta:

Hay uno quetiene unos lotes en camino a Alta Gracia y decía quele com práramos el lote para hacer un geriátrico así estamos todos juntos. Y a medida que nos vamos muriendo en la parte de atrás nos van tapando. O sea, si se toca [el tema de la muerte], pero... con humor.

(AA, varón de 71 años)

Estos dos últimos relatos permiten evocar la noción socialmente conocida como humor negro. La cual, puede ser interpretada como una "posibilidad estética que sugiere una emancipación del sujeto, pero también un espíritu de comunidad, que le presente la oportunidad de una conciencia crítica, como antecedente para una transformación de sí mismo y de su entorno" (Quezada, 2015, p. 88). Si bien, se trata de una categoría compleja, en tanto carece de una definición universalmente consensuada, es posible alegar que la noción discurre, desde el humor, en torno a temas o expresiones considerados tabúes, trágicos o penosos. Al decir de Breton (1991), aunque las fronteras son numerosas (la tontería, la ironía escéptica, la broma sin gravedad) el humor negro es sobre todo el enemigo mortal del sentimentalismo. Como estrategia discursiva es un tipo de humor que apela a la desidentificación y al consuelo cómico de manera hilarante para desdramatizar.

El hu mor negro da fe de un esfuerzo, de un trabajo de la psique ante ese punto de horror o de fascinación de un goce in sospech ado que r resuena y hace eco en la estructura subjetiva, sin garantía de resolución, pero a salv o si se le agr ega resolución con buenos o malos chistes (Coppin \& Gaspard, 2017, p. 153).

Estos autores afirman que el humor negro permite un cierto distanciamiento del sujeto frente a una experiencia mortificante para reivindicarse y afirmarse como sujeto todavía. Sin embargo, la apelación al humor (negro) no siempre cuenta con un sentido de lo apropiado para los interlocutores, es decir, lo que es correcto en determinado momento. Y, en consecuencia, no siempre es garantía de risa y goce asegurado. En un encuentro familiar, una entrevistada expresa el sufrimiento padecido por una broma de su hermana al referir a la compra de una parcela donde depositar sus restos:

(E): El otro día [a mi hermana] se le había dado por contarles que se había com prado una parcela, estaba chocha [contenta] (...) "así que ya tengo don de me pongan y yo quiero que a mí me lloren. Y que me pinten"y se habían puesto a hablar en chiste, perov os sabes que me empezó a hacer mal. Entonces yo 
les digo "¿por qué no hablan de otra cosa?". Pero eso es a raíz de la enfermedad porqueyotengo miedo que a mí me pase algo (...)

(Inv): ¿Esos tem as de conversación su elen salir cuando se junta con alguna amiga?

(E): No, no. Tan es así que cuando ayer estaba mi otra hermana... porque ella no tiene destino, es la cordobesa neta, la quetiene la cosa en la boca y te la larga. Ella tiene que estar cóm oda cuando te hace la broma, pero cuando te la hace te matas de risa. Entonces estaba mi hija y mi hermana y ellas se mataban de risa en tre las dos. Porque iban a estar juntas porqueno sé qué cosa... y yo estaba sufriendo al punto que les dije "bu eno cambien de conversación" porque me hacía mal. "Uy no te v oy a poder contar todolo que nos hem os reído ayer" dice, y bueno em pezó a contar. Perono, ese tema no se toca para nada.

(OC, mujer de 72 años)

Debido a la enfermedad padecida en un pasado reciente, el temor de que algo le suceda es accionado a partir del relato de su hermana, quien bromea con su parcela, aunque sin identificar el malestar provocado con sus comentarios. "La enfermedad grave y la proximidad de la muerte pueden revelar ese real inasimilable" (Coppin \& Gaspard, 2017, p. 153). Aunque la entrevistada reconoce que se trata de un diálogo en clave de humor, ya que, refiere a su hermana como "la cordobesa neta, la que tiene la cosa en la boca y te la larga", solicita cambiar detema de conversación. Incluso, reconoce que su hermana "tiene que estar cómoda cuando te hace la broma”, por lo cual, se presume, que la situación de intimidad y confianza habría operado como garantía para la expresión humorística. Sin embargo, existen diferentes estilos de humor potencialmente beneficiosos o perjudiciales (Martin, 2001). Se identifica que la situación relatada sucede en un marco de vínculos familiares y relaciones positivas, de ahí que la broma emplee una visión humorística, aunque también realista de la vida: "así que ya tengo donde me pongan y yo quiero que a mí me lloren. Y que me pinten".

De modo que en lo que a la muerte se refiere como tema de conversación, el relato pone en evidencia dos aspectos. Por un lado, que no siempre la situación es propicia para el humor, aunque haya espacio para él. Y, por otro, que algunas personas aquejadas por dolencias o enferm edades (presentes o pasadas) rechazan los chistes o las bromas vinculadas a la muerte debido a la imposibilidad de tomar distancia emocional en torno a un relato, aunque esté atravesado por el humor. Para reírse o bromear, uno mismo y/o con otros, el juego del humor requiere de la des-identificación para no ser interpretado como amenaza, burla o provocación. Por lo que, en algunas ocasiones, habría lugar para el humor en torno a la muerte si es lo apropiado, es decir, si es lo correcto en determinado momento para determinada persona.

Pers pectivas de la Comunicación - Vol. 14 - No2 - 2021 - pp. 95-125

Universidad de la Frontera - Chile 
La conexión con el humor al referir a la muerte puede suceder ante cualquier tipo pregunta o intercambio si hay disposición, confianza y complicidad para el sentido del humor. Al respecto, las personas entrevistadas rememoran anécdotas en las que este articula el diálogo durante la entrevista cuando se relata el recuerdo en tono cómico. Es decir, el sentido del humor es rememorado o la re-significación actualiza el recuerdo en clave humorística. Luego de un prolongado postoperatorio, un varón refiere a una anécdota mientras recibía curaciones de una enfermera:

Un día viene y me mete en un cuartito sobre u na piedra, así como esa [señala la mesa da de su cocina]. Yo y a a costumbrado entonces me tiro ahí y me quedo quieto. Ella se va. Y en eso siento que se abre la puerta. Eran dos [enfermeras] y cuan do estaban cerca mío digo "por finya me estaba cansando", "iAhhh está vivo!” [gritando... risas] Por que era la sala don de ponían a los muertos. Era una piedra de mármol grandota y yo estaba qu ieto. Cuando escu charon que hablaba salieron a los gritos. Y la gallega me dijo "casi las matas de un su sto a las chicas"...

(RA, v arón de 75 ã̃os)

El relato recupera el susto de las enfermeras quienes, al dar por muerto al entrevistado, salieron de la habitación a los gritos al escuchar la voz del entonces paciente. Durante su narración, el entrevistado reseña la reacción de las enfermeras en tono jocoso y reproduce, gritando, la frase pronunciada por ellas: “iAhhh está vivo!”.

Otra anécdota es narrada por una mujer de 64 años quien comenta la conversación mantenida con la empleada de su pareja en torno a la ex esposa de él, ya fallecida:

Por ejemplo, la Chacha [empleada] que dice “yo ca da vez que entro a la casa la veo a María Ester”. No es que la ve, sino que se acu erda. Yole dije "Ay Chacha no me digas quela estás viendo" [risas] que me v oy a la mierda [risas].

(EG, mujer de 64 años)

Aunque el recuerdo esté articulado desde la comicidad, la posibilidad de su aparición trasluce la emergencia del temor. Ambas anécdotas son relatadas en clave de humor y, al mismo tiempo, advierten sobre la reacción de espanto y susto que genera -al menos, para algunas personas- la posibilidad de que una persona muerta, hable o se aparezca. En los diálogos se evoca la presencia de un muerto que, en términos de Derrida (2012), asedia los umbrales entre la vida y la muerte: 
De bien que estamos con mi hija viendotele, se abre la pu erta del secreter o sentís un ruidito entonces con la Gime decimos que es la Dora. La Dora es una amiga que ha sido com pañera mía y que se murió en mis brazos. Fuela primera experiencia de una persona que se muriera en mis brazos. Le dio una ACV en la casa de una pedicura desconocida y la Dora antes de m orirse m e dijo "me muero" y yole dije "ni se te ocurra” (...) Decimos con mi hija “es la Dora” porque ella era así piscueta, andariega, andábamos para todos lados juntas. Yo creo que las almas se com unican a veces con uno en determinado m omento.

(MS, mujer de 67 años)

Aquí se expone otra manera de referir a los muertos en breves comentarios de complicidad familiar en el cotidiano vivir, que aluden a ellos en tanto presencias que se hacen notar pero que no provocan temor para los vivos. Sobre todo, cuando la creencia acerca de la comunicación de las almas justifica la presencia de un ser querido fallecido.

\section{El tabú de la muerte}

El interés por el tabú como tema de indagación y estudio ha sido trabajado en distintas disciplinas a partir de diferentes motivaciones. En el caso del tabú lingüístico, es el temor a lo sobrenatural lo que supone su origen, provocando que ciertas palabras se eviten y se reemplacen por otras; no hablar de lo que no se desea que suceda, cambiarles los nombres a las cosas, todo se incluye dentro del mecanismo del tabú lingüístico, lo cual se presume como elem ento interiorizado entre los hablantes (Calvo, 2011). De manera específica, el tabú de la muerte se explica en autores cuando afirman quela muerte es cotidianamente apartada del paso, relegada de la vista y del lenguaje, al punto de que es negativo o de mal gusto mencionarla (Herrán \& Cortina, 2007). Gorer (1965) afirma que la muerte pública, colectiva y ritualizada del siglo XII se transformó durante el siglo XX en un hecho individual y privado, hasta convertirse en un tema tabú a partir del desplazamiento de las creencias sobrenaturales hacia las creencias seculares. Por su parte, Foucault argumenta que en la sociedad contemporánea la muerte se ha convertido en una especie de tabú debido a la biopolítica, en tanto ejercicio de poder que produce, potencia y gestiona la vida, cuyo epicentro radica en el "hacer vivir y dejar morir", a diferencia del poder soberano enarbolado en el "hacer moriry dejar vivir", es decir, potestad de matary extinguir la vida, al hacer morir o dejar vivir a sus súbditos (Foucault, 1989). Es decir, la muerte se convierte en un ámbito incómodo porque queda fuera del alcance del poder al estar más allá de su ámbito de actuación (Quintanas, 2010).

En este sentido, el interrogante acerca de si la muerte es, o no, un tema tabú, entendiendo esta noción como aquello que es prohibido, ocultado, negado u obliterado, exige el ejercicio

Pers pectivas de la Comunicación - Vol. 14 - No2 - 2021 - pp. 95-125

Universidad de la Frontera - Chile 
de situar la pregunta temporal y espacialmente, contextualizarla, es decir, ubicarla en situaciones y ámbitos específicos. Como expone Guber (2001) los temas tabúes son propios de cada grupo social y de cada sociedad. Si bien, en tanto afirmación hay manifestaciones que lo confirman, estas no necesariamente revisten un carácter universal y homogéneo. Por ello esta investigación no buscó afirmar o negar, unánimey categóricamente, el carácter tabú de la muerte, sino, más bien, se orientó en identificar aquellas situaciones y argumentos que confirmaron o desestimaron tal condición desde la propia biografía y vivencia personal. En algunas ocasiones la categoría tabú emergió en el testimonio de las personas entrevistadas mientras que, en otras circunstancias, la noción se instaló a partir de interrogantes concretos. Al respecto una mujer expresa de manera contundente:

Para mí no es tabú la muerte porque existe. Existir, existe. Es ley de la vida. Porque si nos dio vida... nacemos para morir. No es que nacemos para estar siemprevivos (...) Es ley de la vida y la a cepto como ley de la vida. Y por eso cuando y o hablo con los médicos les digo "doctor y o no tengo un futuro. Yo tengo este presente y a estolo quierovivir lo m ejor posible".

(EG, mujer de 81 años)

En el relato la entrevistada afirma que, dado que la muerte existe, no es un tabú para ella. Es decir, la mera condición de su existencia anula la posibilidad del tabú. Incluso, interpreta a la muerte como "ley de la vida” y, en tanto ley, dice aceptarla como tal. No hay posibilidad de maniobra alguna porque "nacemos para morir. No es que nacemos para estar siempre vivos”. En consecuencia, en conversaciones con su médico afirma no tener un futuro, pero sí un presente, presente que desea vivirlo "lo mejor posible". De modo que la muerte, en tanto ley, rige su vida y su capacidad de proyección en un presente sin futuro.

Si bien algunos entrevistados identifican que, para sí mismos, no es tabú hablar de la muerte, reconocen que para otros sí lo es. Por ello, advierten la necesidad de ser respetuosos evitando el tema si se identifica incomodidad, angustia o malestar.

Para mí el tema de la muerte noes tabú, yolo puedo hablar y a mí no me afecta, pero me cuido con la gente que estoy adelante. Porque hay gentepara la que la muerte es tabú (...) Pero si se da conv ersar el tem a yolo converso sin ningún tipo de problemas y loveo com o algo natural. Hay gente que [dice] "no, no m e hables de eso", "notraigas ese tipo de cosas”, está bien listo. Hay que r espetar los pen sa mientos de cada uno.

(YG, v arón de 72 años) 
En tanto la muerte no es tabú, puede ser objeto de conversación, sin embargo, el relato evidencia la necesidad de tomar recaudos. Es decir, la muerte como tema de conversación se habilita o se anula según quién sea el interlocutor. En este sentido, un testimonio relata sobre el ocultamiento de un suicidio familiar:

[Mi señora] ha empezado a ir a la psicólog a (...) Su ele ir sola, peroyo cuandola a compaño, yola delato, porque mi señora hay cosas que no las cuenta y como la va a ayudar la psicóloga si ella no las cuenta. (...) y se ha olvidado de contarleque un tío abuelo se quitóla vida. Fernan do [psicólogo amigo] dice que hay que contarlo (...) Mi suegra contó m edio a las disparaditas ${ }^{2}$ que él se había quitado la vida. Y después de eso no se habló más por que se v e que m i señor a sigue la política de mi su egra. Entonces se ve que, si ella cuenta que su tío se ha suicidado, para ella, es hablar mal del tío. Pero según Fernando habría que contar todo.

(AT, varón de 75 años)

Aunque la noción de tabú no es mencionada en el relato, se hace presente de manera tácita a partir del olvido de su esposa en torno a la muerte auto provocada de un familiar. Disposición que, según el relato, desciende generacionalmente de madre a hija. El ocultamiento del suicidio por parte de su esposa es interpretado por el entrevistado como "hablar mal del tío". Mientras que, en contraposición, el entrevistado evoca la recomendación de su amigo psicólogo quien “dice que hay que contarlo”, es decir, poner en palabras el suicidio como hecho familiar, en este caso, durante la terapia psicológica.

Otro testimonio, relata la conversación mantenida en un encuentro entre amigos en la que se evocaron las formas de morir y las últimas palabras de los cónyuges:

(E): Usted sabe que por ejem plo hay conversa ciones... esto m e pa só hace u nos días. Se habló de cómo muriómimarido, cómo murió mi esposa, cómo se enfermótal, que le pa sóal otro. Y u na señora al final dice “pero terminemos esta conversación por Dios. Es una de muerte...” así que se cambió de tema porque era de pura muerte, de cóm o murió mi marido... uno decía, "mi señora me decía agarrame la m ano, a pretamela fuerte. Yola a garréa sí, la a pretéy a hí nomás quedó m uerta”. Bueno, y la otra también explicó el fallecimiento de su marido y... [risas] una dijo, “cortemos por favor” [risas] porque no sé si será, no sé si trae malestar para uno. A mí no, no me hace nada. Com o digoy o, la muerte cuandollega que se lev a a hacer. Pero a veces son temas que hay muchos que nolotoleran.

(Inv ): ¿Usted identifica qu ehay muchas personas que nolotoler an cuando se habla?

2 Expresión coloquial para referir a una mención a la ligera, sin profundizar, ni ahondar en el tema.

Pers pectivas de la Comunicación - Vol. $14-N^{0} 2-2021-$ pp. 95-125

Universidad de la Frontera - Chile 
(E): Sí, sí, sí. Por ejemplo, esta señora, que es una señora joven, ella le puso fin a esa charla (...) Y se cortó porque se ve que a esa person a nole gustaba mucho hablar de la muerte.

(Inv ): Y ¿̇cree que es un tema para hablar en un ámbito privado, íntimo, o que debería hablarse en espacios más a mplios?

(E): A mí me parecería que no (...) Me parece que no es convenienteporque hay que tratar de vivirla de buen humor. Y ya hablar de enfermedades que tengo el colesterol, que ten gola prótesis, y bueno... y es un tem a que a veces se lo toca y se lo sigue, peroy o creo que no es conv eniente tocar ese tema. Qué se y o no sé si es que uno le tiene miedo, un poco de cuiki3, que se yo. Pero lo mismo, lo tolero, que va a hacer.

(AS, varón de 86 años)

Nótese que la conversación sobre la muerte de los cónyuges efectivamente se sostiene, pero se interrumpe por el pedido explícito de una participante quien solicita cambiar de tema dado el malestar que esta le generaba. Si bien, el entrevistado afirma "A mí no, no me hace nada" luego reconoce "no sé si es que uno le tiene miedo, un poco de cuiki, que se yo. Pero lo mismo, lo tolero, que va a hacer". De modo que, la indiferencia, el miedo y la tolerancia enlazan, en su relato, su actitudy/o su disposición en torno a la muerte y al diálogo sobre la muerte. Cuando se le pregunta si cree que es un tema conveniente para hablar en un ámbito íntimo, o en espacios más amplios, el entrevistado afirma que, aunque a veces se toca y se sigue, no cree conveniente tocar ese tema: "porque hay que tratar de vivirla [a la vida] de buen humor”. Es decir, el humor es evocado como contrapartida. Esto se hace aún más evidente en el siguiente testimonio:

Yo notengo miedo de hablar de la muerte. Y pienso que con las person as queson mis amigas y piensan com oy o, que la muerte existe, que hay que esperarla y que ya llegará en algún momento, pero no creo que sea algo tabú. (...) El otro día sacábamos las cuentas son como 70 años que som os amigas. Y ya v amos quedando pocas. Quedamos tres, cuatro. Nosotras hablamos siem pre, "nov aya a ser que sea la última decimos”... o sea que ya lotom as así... (...) Con humor, con humor sí.

(AL, mujer de 88 años)

Quela muerte no sea considerada tabú, está asociado a dos elementos según lo mencionado: el no tener miedo de hablar al respecto y el compartir una manera de pensar, en este caso,

3 Expresión coloquial para expresar miedo, temor, pánico. 
con sus amigas. Al respecto señala: "Nosotras hablamos siempre”, aunque con la aclaración de que se lo hace desde el humor.

En otro relato se refiere a la cultura asociada a la idea de lo natural para aludir a la muerte, pero que, sin embargo, según los patrones culturales, no se presenta como natural. Por consiguiente, el entrevistado reconoce la condición de tabú por el temor que ésta provoca:

Sí culturalmente tenemos esa... No es algo natural para nosotros la muerte.Y de hecho es tabú porque produce temor. Yo no sé quées, perole ten go miedo a la muerte... nole tengo miedo a la muerte es como que... hay un recitado, a veces me acuerdo, de Hor a cio Guaraní. Que dice "Pero es tan linda la vida, es tan chura el camino que si algún día m em uero entiérrenme en Mendoza, en San Juan, o en Cafayate la her mosa que en vino habré de volver". Es tan linda la vida que uno no se quiere ir de la vida. Yo el temor que le ten go es com o que le van tirando de u na piola. Porque yoy a estoy en edad de merecer. Como que es algo a lo que me resisto y que es natural. No me quiero ir de acá. Porque es irse y no volver nunca más.

(VG, varón de 71 años)

El recitado evocado le permite al entrevistado imaginar y expresar su propia vivencia en relación con la muerte. Si bien, inicia argumentando tener miedo a la muerte, luego aclara: "uno no se quiere ir de la vida". Por lo que su temor se asocia a su deseo de vivir. O sea, menciona la resistencia que le provoca el fin de la vida a pesar de que sería lo natural, sin embargo, también afirma que: "No es algo natural para nosotros la muerte”. Por lo que, su propia vivencia, condensada a su vez en un recitado folclórico, es reconocida en un sentir social ampliado.

La tensión paradójica entre lo natural y lo no natural como significación, da cuenta del sentido de la muerte en tanto orden y en tanto valor; coexistiendo en contradicción. Es decir, así como se nace, también se muere. De modo que el sentido de orden ubica a la muerte al final de todo curso de vida, de ahí su condición de natural. No obstante, el sentido de la muerte en tanto valor se expresa en la dificultad de asumir su carácter inevitable, lo cual es vivido desde un nosotros (cultura occidental) como no natural, favoreciendo, en consecuencia, la emergencia del tabú de la muerte.

Asimismo, una mujer a quien se le pregunta sobre el tabú de la muerte recupera en su relato la visualización de un video. El diálogo ocurre a pocos meses de la muerte de su madre, de manera que la pregunta se enmarca y es interpretada desde el proceso de duelo que transita:

Pers pectivas de la Comunicación - Vol. 14 - No2 - 2021 - pp. 95-125

Universidad de la Frontera - Chile 
Viendo el videoy a no es más tabú pa ra mí. Aparte sabemos que por mis creencias y por cómo me criaron a mí, que todas las per sonas que se mueren van al cielo. Eso nos decían a nosotros "se m u rióla abuelita. Ya está en el cielo, está descansando". Entonces uno se quedaba, pero cuando uno es más grande... "¿a dón de va?"[piensa y se pregunta] ¿¿qué luz hay?", "¿dónde v an las almas?"(...) Entonces hay algo que no sabem os porque estamos en un planoter renal. No, no es tabú. Ahora lotengobien claro.

(SD, mujer de 65 años)

Ante la muerte de personas cercanas, lasimágenes del cielo y el descanso son evocadas como significaciones de las creencias recibidas en la infancia, las cuales son articuladas con interrogantes acerca del destino de las almas y la existencia de la luz. Aquí se evidencia lo que Castoriadis (2010) denomina la lógica ontología heredada. Es decir, los hábitos de pensamiento que las creencias y la crianza ponen a disposición en su presente, aportando sentido y orientación al inducir formas de interpretación. Los distintos elementos de su tradición personal y familiar se combinan en el testimonio y respaldan la referencia al video visualizado. Ante la pregunta sobre el tabú de la muerte, la entrevistada asegura: "viendo el video ya no es más tabú para mí”. Es decir, la noción de tabú trasluce el temor asociado a la muerte luego del fallecimiento de su madre. Sin embargo, el video referenciado, que alude al proceso de transición del moribundo, la alivia, alejando temores. Por lo que, el mensaje audiovisual proporciona una novedad sobre la transición que atraviesa quien muere en los últimos momentos de vida. Una nueva significación se crea e impacta en la concepción acerca de la muerte que le permite re-significar la noción de tabú: “No, no es tabú. Ahora lo tengo bien claro". El proceso personal de construcción de sentido en torno a la muerte en general y a la noción de tabú en particular, le aporta a la entrevistada orden en su duelo. Es decir, certidumbre y previsibilidad al conocer que su madre moribunda fue buscada por sus seres queridos; información que le aporta alivio y sosiego en el transcurso del duelo.

En suma, a partir de los diversos relatos se identifica que el tabú en torno a la muerte se reconoce en dos niveles. Por un lado, en un nivel referido a la autopercepción acerca de la muerte como tabú para sí mismo; disposición de reconocimiento necesaria e ineludible en tanto condición previa para el diálogo. Y, por otro lado, en un nivel donde se reconoce la presencia o la ausencia del tabú en torno a la muerte en una dimensión netamente dialogada, asumiendo diferentes características según los interlocutores y el escenario discursivo. En este segundo caso, las propias percepciones se articulan con las de otros interlocutores, quienes, en el marco de un contrato tácito o explícito, desarrollan conversaciones sobre la muerte de distinto tenor y profundidad. Esto condice con el planteo de Elias (2009) acerca de que la represión de la muerte se realiza en un doble sentido, en un plano individual y en 
un plano social. En lo que respecta al plano individual, cabe mencionar la investigación de Pochintesta (2011), quien afirma que los viejos mayores de 80 años pueden hablar sin tapujos de su propia muerte, por lo que, esta deja de ser tabú, ya que, impera la aceptación no como un destino fatal sino como parte de la vida. Con lo cual, el presente análisis no niega los resultados de la investigadora, al contrario, los confirma. Sin embargo, aquí se distingue y diferencia, entre lo que dicen las personas sobre sí mismas acerca de la posibilidad de mantener conversaciones sobre la muerte y, por otro lado, lo que efectivamente sucede en espacios de intercambio.

\section{Discusión}

\subsection{El diálogo sobre la muerte}

A lo largo de las entrevistas realizadas se identificó que las conversaciones sobre la muerte no aparecen, necesariamente, con frecuencia ni en formas fijas o estables. Es decir, si bien es un tema del cual se habla, se conversa o se bromea, no se vislumbra recurrente; no constituye uno de los temas sobre lo que más se conversa. Asimismo, esta surge en formas, enfoques y situaciones diversas. En las conversaciones que las personas mayores sostienen con sus pares, el sentido de oportunidad no solo es significativo para reconocer cuando el humor es un aliado en las expresiones donde la muerte asume con protagonismo, sino también, para registrar cuando los diálogos acerca del tema presentan rasgos tabúes; entendiendo que el tabú acciona en lugares, en acciones, en la lengua, en personas y en situaciones (Calvo, 2011). Es decir, el sentido del humor y el tabú hacia la muerte no constituyen dos elementos emergentesautónomos eindependientes por sí mismos, sino que están entramados en el marco de contratos de conversación que se fundamentan como sistema de reconocimiento recíproco (Charaudeau, 2006) en todo intercambio lingüístico. De manera que en los encuentros operan mecanismos de apertura y de cierre al diálogo, donde el despliegue de los recursos personales e interpersonales cobra especial importancia. Así como en los relatos se detectó incomodidad y malestar (concreto o presunto), tensión emocional, empatía, compasión, también aparecieron guiños y gestos de complicidad, confabulación, inspiración, imaginación, creatividad, resignación, toleranciay miedo. O sea, los rasgos de inclusión/exclusión que intervienen en el sostenimiento o abandono de conversaciones en torno a la muerte son abundantes y de diversa naturaleza, ya que, median factores cognitivos, emocionales, de conducta, relacionales, culturales y contextuales.

Pers pectivas de la Comunicación - Vol. 14 - No2 - 2021 - pp. 95-125

Universidad de la Frontera - Chile 
Los diferentes relatos seleccionados recopilan breves fragmentos de conversaciones acontecidas en el marco de situaciones cotidianas y efímerasintervenciones, otras en cambio suceden en circunstancias de intimidad familiar o de amistad. Por lo que, en ocasiones, cuando hay lugar para los chistes y bromas que exponen o insinúan a la muerte como argumento protagónico o accesorio de diversión, complicidad y/o sarcasmo -motivación pragmática que se fundamenta en el "pasarla bien" o "vivir la vida de buen humor" - esto no garantiza, necesariamente, el diálogo en torno al tema o, viceversa, no todas las conversaciones en torno a la muerte habilitan el recurso del humor. Sin embargo, esteúltimo se vislumbra como estrategia disruptiva, la cual es legitimada o rechazada según las condiciones de aparición abarcando tanto la emocionalidad personal como el vínculo con quien se sostiene el diálogo. De modo que, el humor se utiliza para burlar la (propia) muerte, enfrentar temores, aliviar o disipar tensiones, es decir, oficia de válvula de escape para afrontar temas considerados dolorosos, irreverentes, vedados o negados. Pero también desde el humor se activan temores cuando la muerte asoma como protagonista o de telón de fondo. Es decir, el sentido del humor en torno a la muerte es un timón que se gira de manera cómplice o de manera irreverente.

Tal como expone Cabrera (2006) acerca de que las significaciones sociales están referidas a un marco social del que forman parte y dentro del cual poseen una efectividad práctica en la configuración del sistema de creencias y de la acción colectiva, la detección de la muerte como tema de conversación, revela las dimensiones significantes que intervienen. Por ello, aunque en el análisis se diferenció entre el tabú de la muerte y el sentido del humor, estas figuras sólo sintetizan, en tanto emergentes, el accionar de los componentes lingüísticos y paralingüísticos que dan lugar a esas formas. Sin embargo, éstas no agotan ni saturan los modos posibles de obstrucción o habilitación del diálogo sobre la muerte. Tan solo, se ofrecen como indicadores.

Las creencias, las disposiciones y las emociones permean constantemente las conversaciones, instituyendo una realidad personal y colectiva sobre la muerte. Ya que, las significaciones que se construyen y reproducen, incluso aquellas que operan de manera tácita, instituyen lo real en torno a la muerte, configurando para cada persona su propio mundo real; donde la experiencia oficia de mediadora entre la estructura y la conciencia sociales (Scott, 2001; Garazi, 2016). En diferentes relatos se divisa que la muerte despierta temores, por lo que, las evasivas y la postergación en las conversaciones es un recurso utilizado ante el rechazo que esta genera, sobre todo cuando involucra de manera directa a un ser querido; ahí la muerte se torna cercana y el contacto con la finitud de la vida es de mayor magnitud. 
Como afirma Scott (2001) el sujeto es constituido discursivamente, por lo tanto, las conversaciones que se incentivan se anulan o postergan no solo abren $\mathrm{u}$ obstruyen posibilidades de intercambio en torno a la temática, sino que accionan en la propia subjetividad, ya que, esta posee "una dimensión dialógica en tanto la producción de sentidos es inseparable de los sistemas de comunicación en que el sujeto está implicado" (González, 2006, p. 19). El proceso conversacional permite la expresión de los deseos, inquietudes y sentimientos y, en definitiva, elaborar la idea de finitud como experiencia humana e insondable (Marshall, 1975). Por lo que, el lenguaje es una plataforma propicia para la elaboración de la presencia de la muerte en el curso vital. Sin embargo, durante algunos encuentros interpersonales no siempre se despliegan condiciones favorables de escucha, apertura y/o profundización del diálogo en torno a esta, ya sea, porque no se prioriza la inquietud o la necesidad de la otra persona -cualesquiera sean los motivos-, porque se interponen las propias concepciones o el ánimo personaly/o porque no se legitima al diálogo en sí mismo como dispositivo para “ciertos temas". Aunque, son circunstancias que revisten características particulares según quienes oficien de interlocutores, hay indicios que muestran que esto sucede tanto con hijos/as, progenitores y/o pares.

En síntesis, así como la realidad no es dicotómica ni transparente, toda experiencia se encuentra mediada por la atribución de significados según la disponibilidad de ciertas categorías en el sistema relacional de significación desde el cual se opera; sistema que incluye tanto la autopercepción como el vínculo intersubjetivo (López, 2012). El abordaje de este eje de indagación da cuenta de que la presencia de la muerte en la trama comunicacional es un asunto complejo que, inevitablemente, se entrama con la biografía en las diferentes formas que asuma. Así como para algunas personas mayores la expresión de un deseo o una inquietud acerca de la (propia) muerte es una necesidad -medien o no negociaciones retóricas-donde, como contrapartida, la receptividad para el diálogo se torna una exigencia. Para otras, en cambio, el asunto no se expone de manera explícita como requerimiento de elaboración discursiva, aunque se participe en espacios de intercambio lingüístico.

\section{Financiamiento}

Esta investigación fue financiada a través de una beca doctoral (2015-2020) del Consejo Nacional de Investigaciones Científicas y Técnicas de Argentina.

\section{Conflicto de interés:}

La autora declara que no tiene conflicto de interés. 


\section{Referencias bibliográficas}

ARIÈS, P. (2008): Morir en Occidente. Buenos Aires, Adriana Hidalgo editora. (2011): El hombre ante la muerte. Buenos Aires, Taurus.

BERENGUER, A., FERNÁNDEZ, M. \& PONS, M.(2014). Escuchar, observary comprender. Recuperando la narrativa en las ciencias de la salud: aportaciones de la investigación cualitativa. Barcelona, Institut Universitari d'Investigació en Atenció Primària Jordi Gol.

BRETON, A. (1991): Antología del humor negro. Barcelona, Anagrama.

CABRERA, D. (2004): Imaginario social, comunicación e identidad colectiva. Artículo presentado en el Diálogo "Comunicación y diversidad cultural". Forum Barcelona, Institut de la Comunicació-Universitat Autònoma de Barcelona. Recuperado el 3 de mayo de $2016 \quad$ de https://www.rua.unam.mx/portal/recursos/ficha/84906/imaginario-socialcomunicacion-e-identidad-colectiva

CABRERA, D. (2006): Lo tecnológico y lo imaginario. Las nuevas tecnologías como creencias y esperanzas colectivas. Buenos Aires, Biblos.

(2007): Imaginario, autonomía y creación cultural en el pensamiento de C. Castoriadis. Devenires VIII(16), pp. 117-135. Instituto de Filosofía, Universidad Veracruzana.

(2008): Imaginarios de lo imaginario. En D. Cabrera (Coord.), Fragmentos de caos. Filosofía, sujeto y sociedad en Cornelius Castoriadis (pp. 15-36). Buenos Aires, Biblos.

CALVO,A. (2011): Sobre el tabú, el tabú lingüístico y su estado de la cuestión. Káñina, 35(2), pp. 121-145. Recuperado el 3 de marzo de 2019 de https://www.redalyc.org/articulo.oa?id=44248790011 
CARBELO, B. \& JÁUREGUI, E. (2006): Emociones positivas: humor positivo. Papeles del Psicólogo, 27, pp. 18-30. Recuperado el 19 de septiembre de 2019 de https://dialnet.unirioja.es/servlet/articulo?codigo $=1417555$

CARRETERO-DIOS, H., PÉREZ-MELÉNDEZ, C. \& BUELA-CASAL, G. (2006): Dimensiones de la apreciación del humor. Psicothema, 18(3), pp. 465-470. Recuperado el 19 de septiembre de 2019 de http://www.psicothema.com/psicothema. asp?id=3239

CASARES, J. (2002): Concepto del humor. CIC, Cuadernos de Información y Comunicación, (7), pp. 169-187. Recuperado el 19 de septiembre de 2019 de https://revistas.ucm.es/index.php/CIYC/article/view/CIYCo202110169

CASTORIADIS, C. (2010): La institución imaginaria de la sociedad (Tomo I y II). Argentina, Ensayo.

CHARAUDEAU, P. (2006): El contrato de comunicación en una perspectiva lingüística: normas psicosociales y normas discursivas. Opción, 22(49), pp. 38-54. Recuperado

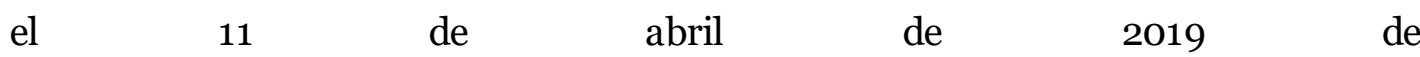
http://ve.scielo.org/scielo.php?script=sci_arttext\&pid=S101215872006000100004

CONSEJO NACIONAL DE INVESTIGACIONES CIENTÍFICAS Y TÉCNICAS (2006): Lineamientos para el comportamiento ético en las Ciencias Sociales y Humanidades, Resolución 2857/o6. Buenos Aires, CONICET. Recuperado el 9 de noviembre de 2017 de http://www.conicet.gov.ar/wp-content/uploads/RD20061211-2857.pdf

COPPIN, M. \& GASPARD, J. L. (2017): El humor negro frente a la muerte. Desde el jardín de Freud: revista de psicoanálisis, (17), pp.149-160. Recuperado el 10 de septiembre de 2019 de https://revistas.unal.edu.co/index.php/jardin/article/view/65522

DENZIN, N. K. \& LINCOLN, Y. S. (1994): Introduction: Entering the Field of Qualitative Research. En N. K. Denzin \& Y.S. Lincoln (Eds.), Handbook of Qualitative Research. California, Sage. 
DERRIDA, J. (2012): Espectros de Marx. El estado de la deuda, el trabajo del duelo y la Nueva Internacional. En J. Derrida, Espectros de Marx. El estado de la deuda, el trabajo del duelo y la Nueva Internacional (Cap I-V). Madrid, Editorial Trotta.

DITTUS, R. (2006): El imaginario social y su aporte a la teoría de la comunicación: seis argumentos para debatir. Cinta moebio, 26, pp. 166-176. Recuperado el 8 de marzo de 2018 de https://www.moebio.uchile.cl/26/dittus.html

ELIAS, N. (2009): La soledad de los moribundos. México, Fondo de Cultura Económica.

ERICKSON, S. \& FELDSTEIN, S. (2007): Adolescent humor and its relationship to coping, defense strategies, psychological distress, and well-being. Child Psychiatry and Human Development, 37, pp. 255-271. Recuperado el 2 de octubre de 2018 de https://link.springer.com/article/10.1007/s10578-006-0034-5

FERNÁNDEZ-ABASCAL, E. G. (2009): Emociones Positivas. Madrid, Editorial Pirámide.

FOUCAULT, M. (1989): Derecho de muerte y poder sobre la vida. En M. FOUCAULT, Historia de la sexualidad I. La voluntad de saber (pp. 161-194). Madrid, Siglo XXI.

FREUD, S. (1915): De guerra y muerte. Temas de actualidad. En S. Freud, Obras completas (Vol. 14). Buenos Aires: Amorrortu.

GARAZI, D. (2016): Experiencia, leguaje e identidad: Algunas notas sobre el concepto de experiencia en la obra de Joan W. Scott. Trabajos y Comunicaciones, 2da Época, 43, pp. 1-11. Recuperado el 9 de diciembre de 2017 de https://repositoriosdigitales.mincyt.gob.ar/vufind/Record/MemAca_b43ea8e5461 f546c3595a107ad757co5

GLASER, B. \& STRAUSS, A. (1967): The Discover of Grounded Theory: strategies for qualitative research. Chicago, Aldine.

GONZÁLEZ, F. L (2006): La subjetividad como definición ontológica del campo psi; repercusiones en la construcción de la psicología. Revista de Psicología, 2(4), pp. 5- 
29. Recuperado el 2 de diciembre de 2019 de https://repositorio.uca.edu.ar/handle/123456789/6004

GORER, G. (1965): Death, grief and mourning in contemporary Britain. London, The Cresset Press.

GUBER, R. (2001): La etnografía, método, campo y reflexividad. Bogotá, Norma.

HERNÁNDEZ-SAMPIERI, R., FERNÁNDEZ-COLLADO, C. \& BAPTISTA-LUCIO, P. (2014): Metodología de la Investigación. México D. F., McGraw-Hill.

HERRÁN, A. \& CORTINA, M. (2007): Introducción a una pedagogía de la muerte. Educación y Futuro, 17, pp. 131-148. Recuperado el 5 de junio de 2016 de https://www.redalyc.org/articulo.oa?id=77100806

KUIPER, N. A., GRIMSHAW, M., LEITE, C. \& KIRSH, G. (2004): Humor is not always the best medicine: Specific components of sense of humor and psychological well-being. Humor: International Journal of Humor Research, 17(1-2), pp. 135-168. https://doi.org/10.1515/humr.2004.002 Recuperado el 19 de junio de 2019 de https://psycnet.apa.org/record/2004-14432-007

LABARCA, C. (2012): Sentido del humor en el adulto mayor. Telos, Revista de Estudios Interdisciplinarios en Ciencias Sociales, 14(3), pp. 400-414. Recuperado el 19 de junio de 2019 de https://www.redalyc.org/articulo.oa?id=99324907012

LÓPEZ, D. (2012): La prueba de la experiencia Reflexiones en torno al uso del concepto de experiencia en la historiografía reciente. Prismas, Revista de historia intelectual, 16(1), pp. 33-52. Recuperado el 4 de abril de 2018 de https://www.redalyc.org/articulo.oa?id=387036814002

LOUE, S., COMITÉ CENTRAL DE BIOÉTICA \& MOLINA, D. P. (2015): Las consideraciones éticas sobre la vulnerabilidad en la investigación cualitativa. Revista Facultad Nacional de Salud Pública, 33(1), pp. 128-130. Recuperado el 9 de noviem bre de 2017 de http://bibliotecadigital.udea.edu.co/handle/10495/4443

Pers pectivas de la Comunicación - Vol. 14 - No2 - 2021 - pp. 95-125

Universidad de la Frontera - Chile 
MARSHALL, V. (1975): Socialization for impending death in a retirement village. The American Journal of Sociology, 80(5), pp. 1124-1144. Recuperado el 25 de junio de 2017 de https://www.journals.uchicago.edu/doi/abs/10.1086/225947

MARTÍN, E. (1998): Los decires y los haceres. Papers, 56, pp. 57-71. Recuperado el 18 de abril de 2019 de https://papers.uab.cat/article/view/v56-martin

MARTIN, R.A. \& FORD, T. E. (2007): The psychology of humor. An integrative approach. USA, Elsevier.

MARTIN, R. A. (2001): Humor, laughter, and physical health: Methodological issues and research indings. Psychological Bulletin, 127, pp. 504-519. Recuperado el 19 de junio de 2019 de https://pubmed.ncbi.nlm.nih.gov/11439709/

MAURER, C. (2008): Does humor contribute to successful aging? Dissertation Abstracts International, 68(10-A).

MURILLO, J. (2003): Teoría Fundamentada o Grounded Theory. Madrid, Universidad Autónoma de Madrid.

PINTOS, J. L. (2005): Comunicación, construcción de la realidad e imaginarios sociales. Utopia y Praxis Latinoamericana, 10(29), pp. 37-65. Recuperado el 7 de febrero de 2020 de https://www.redalyc.org/articulo.oa?id=27910293

POCHINTESTA, P. (2011): Esbozos de una construcción de la finitud en los mayores de ochenta años: de la negación a la aceptación. Psicología y Salud, 21(2), pp. 273-286. $\begin{array}{lllllll}\text { Recuperado } & \text { el } & 1 & \text { de } & \text { junio } & \text { de } & 2016\end{array}$ https://psicologiaysalud.uv.mx/index.php/psicysalud/article/view/580

POCHINTESTA, P. (2012): Concepciones acerca de la propia muerte en la gran vejez. Palabras mayores, 4(8). Recuperado el 1 de junio de 2016 de http://repositorio.pucp.edu.pe/index/handle/123456789/21451

QUEZADA, A. (2015): Antología estética del humor negro: la risa como toma de conciencia, medio de reflexión y praxis colectiva. Pensamiento, papeles de filosofía, 1(2), pp. 87- 
115. Recuperado el 11 de octubre de 2019 de https://revistapensamiento.uaemex.mx/article/view/3966/2650

QUINTANAS, A. (2010): El tabú de la muerte y la biopolítica según M. Foucault. Revista Internacional de Filosofía, 51, pp. 171-182. Recuperado el 1 de agosto de 2019 de https://revistas.um.es/daimon/article/view/148581

SCOTT, J. (2001): Experiencia. La ventana, 2(13), pp. 42-73. Recuperado el 9 de diciembre de 2017 de http://revistalaventana.cucsh.udg.mx/index.php/LV/article/view/551

VASILACHIS, I. (2006): La investigación cualitativa. En I. Vasilachis (Coord.), Estrategias de investigación cualitativa (pp. 23-64). Barcelona, Gedisa. 